\title{
Poly(alkylene oxide) Ionomers. V. Polymers and Copolymers of Cyclic Ethers with Pendant Carboxylate Groups*
}

\author{
O. Vogl, J. Muggee, and D. BANSLEben \\ Polymer Science and Engineering Department, University of Massachusetts, \\ Amherst, Massachusetts 01003, U.S.A.
}

(Received April 15, 1980)

\begin{abstract}
Alkenonic acids, methyl $\omega$-alkenoates, and methyl $\omega$-epoxyalkanoates of 3 to 11 carbon atoms with $\left(\mathrm{CH}_{2}\right)$ spacer groups between the epoxy ring and the carboxyl group have been synthesized and are being characterized. The compounds which have $1,2,5$ and $8 \mathrm{CCH}_{2} \rightarrow$ groups were selected for more extensive studies including polymerization and copolymerization studies. With an aluminumalkyl-water initiator modified with acetylacetone $\left(\mathrm{AlEt}_{3}-\mathrm{H}_{2} \mathrm{O}-\mathrm{AcAc}\right.$, $1: 0.5: 1)$, methyl $\omega$-epoxyalkanoates have been polymerized to polymers of moderate to high molecular weight (for $n=8, M_{n}=2.5 \times 10^{5}$ ), and copolymerized with such cyclic ethers as ethylene oxide, propylene oxide, and $n$-hexene oxide. Investigations of the copolymerizations of $\omega$ epoxyalkanoates with other cyclic ethers and the use of other modified aluminumalkyl-water systems as initiators are now underway. Classical cationic initiators for $\omega$-epoxyalkanoate polymerizations have not resulted in the formation of high polymers although the epoxides were not present after several days of reaction.

KEY WORDS Epoxidation / $\omega$-Alkenoic Acid / Methyl $\omega$-Alkenoates / Methyl $\omega$-Epoxyalkanoate / Spacer Group / Aluminumalkyl Modified Initiator / Copolymers /
\end{abstract}

Polymers with pendant functional groups exhibit interesting polymer properties characteristic for those of the main chain ,or those typical of the substituent or a combination of these properties. Although much of the early work on polymers with functional groups was concerned with polymers with polyethylene backbone chains, more recently polymers with polyether ${ }^{1,2}$ or polyacetal backbone chains have become known. ${ }^{3-9}$ The work on functionally substituted polyethers has developed in two different directions: (a) homopolymerization of epoxides with carboxylate groups directly attached to the poly(oxyalkylene) chain (polyglycidates), and (b) copolymerization of glycidates with various cyclic ethers and investigation of the properties of these polymers. (These substituted polyethers have the pendant carboxylate groups directly attached to the polyether backbone chain.) In addition to these two areas, new interest has developed for the preparation of monomers which have the functional

* Part IV: W. J. MacKnight, L. DeMejo, and O. Vogl, Acta Polymerica, in press. groups separated with a spacer group from the polymerizable group and for polymerization of these monomers.

Attempts to polymerize $\omega$-alkenoates to highmolecular-weight polymers have largely been unsuccessful, especially when coordination initiators of the transition-metal type were used; ring-opening polymerization of functionally substituted bicycloheptenes by metathesis was, however, successful in isolated cases. ${ }^{10,11}$

The polymerization of cyclic ethers with cationic and coordinative anionic polymerization initiators using aluminum and zinc compounds has been studied in the past. ${ }^{1,12}$ This work consisted almost exclusively of polymerization studies of unsubstituted cyclic ethers such as ethylene oxide, oxetane or tetrahydrofuran. The polymerization of epoxides with alkyl substituents (propylene oxide), chloromethyl substituents (epichlorohydrin), and ether substituents (glycidyl ethers) has also been studied. ${ }^{1,2}$ Polymerization of ethyl glycidate has been described in a patent. ${ }^{13}$ Only recently has 
the polymerization of ethyl glycidate (EG) with triflate ester initiators been studied more extensively. ${ }^{7,8}$ EG has also been incorporated into poly(oxymethylene) $\mathrm{s}^{3-5}$ by solution copolymerization with trioxane, and by a technique where EG and trioxane or, in a terpolymerization, EG, trioxane, and 1,3-dioxolane were mixed in the gas phase; the initiator was added above the ceiling temperature and the polymerization was achieved by quenching of the gaseous mixture.,

An interesting copolymer of EG and THF was also prepared at room temperature with triethyloxonium tetrafluoroborate or ethyl triflate as initiators. $^{8}$

Successful copolymerizations of EG with a number of substituted epoxides and oxetane have been achieved with organometallic initiators. ${ }^{9}$ Many typical aluminumalkyl or zincalkyl initiators modified with water and/or other chelating agents were studied; the most efficient initiator was found to be a triethylaluminum-water-acetylacetone $\left(\mathrm{AlEt}_{3}-\mathrm{H}_{2} \mathrm{O}-\mathrm{AcAc}\right)$ combination, with a component ratio of $1.0: 0.3: 0.5$. Copolymerization of EG with these cyclic ethers gave high-molecularweight copolymers with EG incorporated in only small amounts $(1-4 \mathrm{~mol} \%)$, although the feed ratio of the monomers in these copolymerizations was nearly $1: 1$; under the same conditions and with the same initiator EO-EG mixtures gave only EO homopolymer.

It was the objective of this work to synthesize $\omega$ alkenoates and $\omega$-epoxyalkanoates with $\mathrm{CCH}_{2} \mathrm{~F}_{n}$ connecting groups, where $n$ varied from 0 to 8 , and to characterize these compounds by spectroscopic means with particular emphasis on the detailed characterization of the polymerizable group. It was our further goal to prepare high-molecular-weight polymers from the $\omega$-epoxyalkanoates, and to study the copolymerization of $\omega$-epoxyalkanoates with cyclic ethers with particular emphasis on the copolymerization with ethylene oxide. We are reporting in this paper the major achievement of these goals.

\section{EXPERIMENTAL}

\section{Materials}

3-Butenoic acid (Aldrich Chemical Co.), 4pentenoic acid (Polysciences, Inc.), 10-undecenoic acid (Fisher Scientific Co.), adipic acid (Aldrich
Chemical Co.), and azelaic acid (Aldrich Chemical Co.) were used as received without purification.

Acetylacetone (AcAc) (Tridom Fluka Chemicals), anhydrous ethyl ether (Fisher Scientific Co.), methanol (spectral grade, Fisher Scientific Co.), $\mathrm{BF}_{3}$ etherate (Aldrich Chemical Co.), trifluoromethanesulfonic acid (Aldrich Chemical Co.), antimony pentachloride (Matheson, Coleman and Bell), cupric acetate (Aldrich Chemical Co.), and lead tetraacetate (Aldrich Chemical Co.) were used without further purification.

$m$-Chloroperbenzoic acid $(80-90 \%$, technical, Aldrich Chemical Co.) was purified according to the literature procedure. ${ }^{14}$ Dichloromethane was distilled from $\mathrm{CaH}_{2}$ after washing with $1 \%$ aqueous $\mathrm{NaOH}$ solution, distilled water, and drying over $\mathrm{CaCl}_{2}$. Nitrobenzene was twice distilled under reduced pressure, dried over $\mathrm{P}_{2} \mathrm{O}_{5}$, and distilled under reduced pressure. Benzene was distilled from $\mathrm{Na} / \mathrm{K}$ alloy after washing with concd $\mathrm{H}_{2} \mathrm{SO}_{4}, 5 \%$ aqueous $\mathrm{NaHCO}_{3}$ solution, water and drying over anhydrous $\mathrm{MgSO}_{4}$. Triethylaluminum (Ethyl Corp.) was obtained as a liquid and used as received.

\section{Measurements}

Infrared spectra were taken on neat liquids between salt plates (monomers) or on thin films cast from benzene solution (polymers) on an Infracord IR Spectrometer or a Perkin-Elmer Model 283 Infrared Spectrometer.

NMR spectra were recorded on a Perkin-Elmer R-24 ${ }^{1} \mathrm{H}$ NMR Spectrometer and a Varian CFT-20 ${ }^{13} \mathrm{C}$ NMR Spectrometer.

The transition temperatures were measured on a Perkin-Elmer DSC-2 Differential Scanning Calorimeter at a heating rate of $20^{\circ} \mathrm{C} \mathrm{min}^{-1}$, under nitrogen.

\section{Procedures}

Preparation of $\mathrm{AlEt}_{3}-\mathrm{H}_{2} \mathrm{O}-\mathrm{AcAc}(1.0: 0.5: 1.0)$ Initiator Solution. A large Schlenk tube, equipped with a 3-way vacuum stopcock and a magnetic stirring bar, was evacuated to a pressure of $0.01 \mathrm{mmHg}$ and then carefully flame-dried. The apparatus was alternately filled with dry nitrogen and evacuated ( 3 times) to ensure removal of oxygen.

Triethylaluminum $(1.80 \mathrm{ml}, 13.1 \mathrm{mmol})$ was carefully transferred to the Schlenk tube via a nitrogen-filled syringe while maintaining a heavy 
counter-flow of dry nitrogen through the tube. The tube was then chilled to $0^{\circ} \mathrm{C}$ by partial immersion in an ice-water mixture. The tube was then fitted with a clean, dry $60 \mathrm{ml}$ addition funnel (with side arm) and the apparatus purged with nitrogen for 5 minutes. A solution of AcAc $(1.35 \mathrm{ml}, 13.1 \mathrm{mmol})$ in $40 \mathrm{ml}$ anhydrous diethyl ether was placed in the addition funnel. Dropwise addition of the ethereal solution was carried out with stirring over a 15 minute period and the reaction allowed to proceed at $0^{\circ} \mathrm{C}$ for 2 hours. The system was maintained under a slight positive pressure of nitrogen to allow the removal of ethane gas. Re-distilled water, $0.12 \mathrm{ml}(6.6 \mathrm{mmol})$, was carefully added dropwise to the $\mathrm{AlEt}_{3}-\mathrm{AcAc}$ solution and the reaction allowed to proceed with stirring overnight at $0^{\circ} \mathrm{C}$. The resulting clear, nearly colorless initiator solution was stored under nitrogen in the absence of light at $0^{\circ} \mathrm{C}$. The $\mathrm{AlEt}_{3}-$ $\mathrm{H}_{2} \mathrm{O}_{2}$-AcAc initiator was generally used $1-2$ days after preparation although it was found to maintain a high level of activity for several weeks.

Polymerization of Methyl 10,11-Epoxyundecanoate with $\mathrm{AlEt}_{3}-\mathrm{H}_{2} \mathrm{O}-\mathrm{AcAc}(1.0: 0.5: 1.0)$ Initiator. A $125 \times 20 \mathrm{~mm}$ polymerization tube, fitted with a 3-way pressure stopcock, was evacuated to a pressure of $0.01 \mathrm{mmHg}$ and then carefully flamedried using a Bunsen burner. In order to ensure complete removal of traces of oxygen, the tube was alternately ( 3 times) purged with dry nitrogen and evacuated to $0.01 \mathrm{mmHg}$.

Under a heavy counter-flow of dry nitrogen, the tube was then charged with $3.00 \mathrm{ml}$ methyl 10,11 epoxyundecanoate $(2.90 \mathrm{~g}, 13.5 \mathrm{mmol})$ and $12 \mathrm{ml}$ purified benzene using nitrogen-filled syringes. The contents of the tube were then degassed by the usual freeze-thaw method (three times). Using a dry, nitrogen-filled syringe, $2.15 \mathrm{ml} \mathrm{AlEt} \mathrm{A}_{3}-\mathrm{H}_{2} \mathrm{O}-\mathrm{AcAc}$ ( $0.68 \mathrm{mmol}$ aluminum or $5 \%$ initiator based on epoxide monomer) initiator solution ( 0.32 molar in $\mathrm{AlEt}_{3}$ ) was added and the contents of the tube were thoroughly mixed. The tube was sealed after freezing its contents at liquid nitrogen temperature and evacuating to $0.01 \mathrm{mmHg}$. Polymerization was allowed to proceed for 1 week at ambient temperature in the absence of light. During this period the initially clear, nearly colorless solution gradually increased in viscosity until becoming an immobile, transparent plug.

The tube was opened, and the rubbery plug was dissolved in a mixture of $200 \mathrm{ml}$ benzene, $50 \mathrm{ml} \mathrm{p}$ dioxane and $5 \mathrm{ml}$ anhydrous methanol. The polymer solution was filtered through a coarse grit sintered glass funnel and the volume of the filtrate was reduced to $c a .75 \mathrm{ml}$ on a rotary evaporator. The polymer was precipitated by dropwise addition into $600 \mathrm{ml}$ methanol containing $2 \mathrm{ml}$ concentrated $\mathrm{HCl}$; the precipitate was collected by filtration and washed with $300 \mathrm{ml}$ anhydrous methanol. The polymer was dried at ambient temperature and 0.01 mmHg for 48 hours over $\mathrm{P}_{2} \mathrm{O}_{5}$. The yield of white, elastomeric polymer was $1.40 \mathrm{~g}(48 \%)$. Anal. Calcd. for $\left(\mathrm{C}_{12} \mathrm{H}_{22} \mathrm{O}_{3}\right)_{n}: \mathrm{C}, 67.25 \% ; \mathrm{H}, 10.35 \%$. Found: $\mathrm{C}$, $67.28 \% ; \mathrm{H}, 10.58 \%$. ash $<0.05 \%$. Infrared analysis (as thin film cast on a $\mathrm{NaCl}$ window from $\mathrm{CHCl}_{3}$ ) showed the following characteristic absorptions: $1735 \mathrm{~cm}^{-1}\left(\mathrm{C}=\mathrm{O}\right.$, ester carbonyl) and $1105 \mathrm{~cm}^{-1}$ (C-O-C, ether). The inherent viscosity, $\eta_{\text {inh }}$, (determined at $30^{\circ} \mathrm{C}$ as a $0.5 \%$ solution in $\mathrm{CHCl}_{3}$ ) was $1.8 \mathrm{dl} \mathrm{g}^{-1}$, which corresponds to average molecular weights $M_{n}=248000$ and $M_{w}=578000$ as determined by gel-chromatographic analysis in THF solution. The glass-transition temperature, $T_{\mathrm{g}}$, of the polymer was $-32^{\circ} \mathrm{C}$ as determined by DSC.

Preparation of Propylene Oxide-co-Methyl 4,5Epoxypentanoate Copolymer. A polymerization tube, which had been alternately flamed out at 0.05 $\mathrm{mmHg}$ and purged with dry nitrogen three times, was charged with benzene $(6 \mathrm{ml})$ and methyl $4,5-$ epoxypentanoate $(0.73 \mathrm{ml}, 6 \mathrm{mmol}, 30 \mathrm{~mol} \%$ of monomer feed). PO $(0.98 \mathrm{ml}, 14 \mathrm{mmol}, 70 \mathrm{~mol} \%$ of monomer feed) and the $\mathrm{AlEt}_{3}-\mathrm{H}_{2} \mathrm{O}-\mathrm{AcAc}$ (1.0: $0.5: 1.0)$ initiator $(3.23 \mathrm{ml}, 1 \mathrm{mmol}$ aluminum, $5 \mathrm{~mol}$ $\%$ of monomer feed) were added, the contents of the tube were degassed, and the tube was sealed at 0.05 $\mathrm{mmHg}$. The polymerization was allowed to proceed for 4 weeks at ambient temperature in the dark. The contents of the tube were then frozen in liquid nitrogen and the tube was opened; the mixture was dissolved in benzene $(200 \mathrm{ml})$ and gave a viscous solution which was washed with aqueous $0.1 \mathrm{~N} \mathrm{HCl}$ solution $(100 \mathrm{ml})$, followed by $2 \times 100 \mathrm{ml}$ of distilled water. The solution was freeze-dried for 2 days at ambient temperature and $0.05 \mathrm{~mm}$ and gave a white, tacky elastomer in $51 \%$ yield $(0.8 \mathrm{~g})$. The IR spectrum (sample cast as a film on $\mathrm{NaCl}$ plates) showed carbonyl absorption at $1730 \mathrm{~cm}^{-1}$ and ether absorption centered at $1100 \mathrm{~cm}^{-1} \cdot \eta_{\mathrm{inh}}=1.8 \mathrm{dl} \mathrm{g}^{-1}$ $\left(0.05 \%\right.$ solution in benzene, $\left.30^{\circ} \mathrm{C}\right) . T_{\mathrm{g}}=-51^{\circ} \mathrm{C}$. 


\section{RESULTS AND DISCUSSION}

Functionally substituted epoxides with $1-8$ methylene spacer groups between the epoxy group and the ester functionality have been prepared with special emphasis on the epoxides with spacer lengths $n=0,1,2,5$, and 8 . The epoxides were synthesized by epoxidation of the corresponding $\omega$-alkenoates with $m$-chloroperbenzoic acid. ${ }^{14}$ The $\omega$-alkenoates had been obtained by acid catalyzed esterification of the $\omega$-alkenoic acids; for example, 3-butenoic, 4pentenoic, and 10-undecenoic acids were converted in high yields $(80-90 \%)$ to the methyl esters, a reaction which proceeded without migration of the terminal double bond as revealed by spectroscopic analysis including infrared spectroscopy, ${ }^{1} \mathrm{H}$ and ${ }^{13} \mathrm{C}$ NMR spectroscopy (eq 1 ).

$$
\begin{array}{r}
\mathrm{CH}_{2}=\mathrm{CH}-\left(\mathrm{CH}_{2}\right)_{n}-\mathrm{COOH}+\mathrm{CH}_{3} \mathrm{OH} \stackrel{\mathrm{H}+}{\longrightarrow} \\
\mathrm{CH}_{2}=\mathrm{CH}-\left(\mathrm{CH}_{2}\right)_{n}-\mathrm{COOCH}_{3}+\mathrm{H}_{2} \mathrm{O} \\
n=1,2,5,8
\end{array}
$$

Some of the $\omega$-alkenoic acids were commercially available or their synthesis was known. Several generally applicable syntheses were evaluated for the preparation of methyl $\omega$-alkenoates, including the oxidative decarboxylation of the monomethyl ester of selected dicarboxylic acids in the presence of copper (II) acetate and lead (IV) acetate. Thus, dimethyl adipate and dimethyl azelate were partially hydrolyzed to their corresponding half-esters prior to the oxidative decarboxylation to their respective $\omega$-alkenoates (methyl 4-pentenoate and methyl 7octenoate).

A very interesting and important general method for the preparation of epoxides in the laboratory is the use of the stable organic peracid, $m$ chloroperbenzoic acid. ${ }^{15}$ Epoxidation of the terminal double bond of methyl $\omega$-alkenoates was readily accomplished as shown in eq 2 .

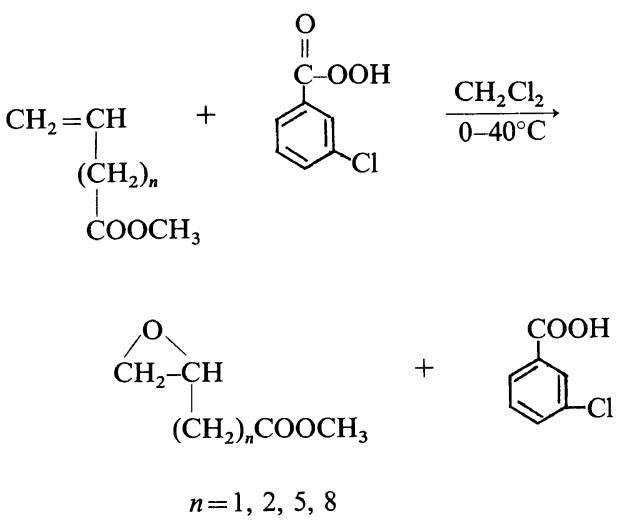

Attractive features of this method are mild reaction conditions (low reaction temperatures) and excellent yields of the epoxide. We have prepared by this method the following epoxides: methyl 2,3epoxypropanoate $(27 \%, n=0)$ (EG), methyl 3,4epoxybutanoate $(90 \%, n=1)$ (MEB), methyl 4,5epoxypentanoate $(92 \%, n=2)$ (MEP), methyl 7,8 epoxyoctanoate $(95 \%, n=5)$ (MEO), and methyl 10,11 -epoxyundecanoate $(78 \%, n=8)$ (MEU). The

\begin{tabular}{|c|c|c|c|c|c|}
\hline Compound & $n$ & Mol wt & bp & Density at $25^{\circ} \mathrm{C}$ & $\stackrel{v}{\mathrm{C}}-\mathrm{C}$ \\
\hline $\begin{array}{l}\text { Methyl 3,4-epoxy- } \\
\text { butanoate }\end{array}$ & 1 & 116.11 & $\begin{array}{c}60^{\circ} \mathrm{C} \\
(13 \mathrm{mmHg})\end{array}$ & $1.111 \mathrm{~g} \mathrm{ml}^{-1}$ & $835 \mathrm{~cm}^{-1}$ \\
\hline $\begin{array}{l}\text { Methyl 4,5-epoxy- } \\
\text { pentanoate }\end{array}$ & 2 & 130.14 & $\begin{array}{c}65^{\circ} \mathrm{C} \\
(7 \mathrm{mmHg})\end{array}$ & $1.072 \mathrm{~g} \mathrm{ml}^{-1}$ & $830 \mathrm{~cm}^{-1}$ \\
\hline $\begin{array}{l}\text { Methyl 7,8-epoxy- } \\
\text { octanoate }\end{array}$ & 5 & 172.21 & $\begin{array}{c}58-60^{\circ} \mathrm{C} \\
(0.05 \mathrm{mmHg})\end{array}$ & $1.000 \mathrm{~g} \mathrm{ml}^{-1}$ & $830 \mathrm{~cm}^{-1}$ \\
\hline $\begin{array}{l}\text { Methyl 10,11-epoxy- } \\
\text { undecanoate }\end{array}$ & 8 & 214.29 & $\begin{array}{c}108-109.5^{\circ} \mathrm{C} \\
(0.6 \mathrm{mmHg})\end{array}$ & $0.968 \mathrm{~g} \mathrm{ml}^{-1}$ & $830 \mathrm{~cm}^{-1}$ \\
\hline
\end{tabular}

Table I. Physical properties of $\omega$-epoxyalkanoates

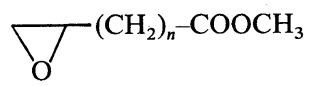


Table II. ${ }^{13} \mathrm{C}$ NMR chemical shift data of $\omega$-epoxyalkanoates ${ }^{\mathrm{a}}$

\begin{tabular}{|c|c|c|c|c|c|c|c|c|c|c|c|c|c|}
\hline \multirow{2}{*}{ Compound } & \multirow{2}{*}{$n$} & \multirow{2}{*}{\multicolumn{2}{|c|}{$\mathrm{C} \longrightarrow{ }^{\alpha} \sim \beta$}} & \multirow{2}{*}{$\underline{\mathrm{C}}=\mathrm{O}$} & \multirow{2}{*}{$\mathrm{OCH}_{3}$} & \multicolumn{8}{|c|}{ Carbon atoms of spacer group ${ }^{b}$} \\
\hline & & & & & & 1 & 2 & 3 & 4 & 5 & 6 & 7 & 8 \\
\hline $\begin{array}{l}\text { Methyl 3,4-epoxy- } \\
\text { butanoate }\end{array}$ & 1 & 51.80 & 46.54 & 170.91 & 48.01 & 37.94 & & & & & & & \\
\hline $\begin{array}{l}\text { Methyl } 4,5 \text {-epoxy- } \\
\text { pentanoate }\end{array}$ & 2 & 51.54 & 46.78 & 173.23 & 51.12 & 27.94 & 30.22 & & & & & & \\
\hline $\begin{array}{l}\text { Methyl 7,8-epoxy- } \\
\text { octanoate }\end{array}$ & 5 & 51.88 & 46.60 & 173.60 & 51.19 & 32.54 & 25.89 & 25.04 & 29.14 & 33.91 & & & \\
\hline $\begin{array}{l}\text { Methyl 10,11-epoxy- } \\
\text { undecanoate }\end{array}$ & 8 & 52.20 & 46.90 & 174.03 & 51.30 & 32.58 & 26.04 & 29.43 & 29.43 & 29.21 & 29.21 & 25.00 & 34.07 \\
\hline
\end{tabular}

a In ppm downfield from $\mathrm{TMS}\left(\mathrm{CDCl}_{3}\right.$ solutions).

b Carbon atom nearest epoxy ring designated carbon atom 1 of spacer group.

good yields in the oxidation of methyl 3-butenoate to MEB suggest that the proximity of the electron withdrawing carbonyl function in $n=1$ did not substantially retard the oxidation of the double bond. Although the rate of epoxidation of methyl 3butenoate $(n=1)$ is slower than that of the higher homologues ( $n=5$ and $n=8$ ), it is substantially faster than the epoxidation of methyl 2-propenoate $(n=0)$ which was accomplished, but with a much lower yield. The epoxidation of $\alpha, \beta$-unsaturated carbonyl compounds like methyl 2-propenoate (methyl acrylate) normally requires the use of trifluoroperacetic acid (from trifluoroacetic anhydride $\left.+90 \% \mathrm{H}_{2} \mathrm{O}_{2}\right) .^{16,17}$

Important physical properties of the $\omega$-epoxyalkanoates are shown in Table I; Table II gives the ${ }^{13} \mathrm{C}$ NMR chemical shift data of the $\omega$-epoxyalkanoates.

Polymerization and Copolymerization of $\omega$ Epoxyalkanoates with Modified Aluminumalkyl Initiators

High-molecular-weight polyethers containing pendant ester groups separated from the backbone by methylene spacer groups have been successfully prepared in our laboratories. MEU was polymerized to high molecular weight $\left(M_{n}=248000\right)$ by a ternary initiator system $\mathrm{AlEt}_{3}-\mathrm{H}_{2} \mathrm{O}-\mathrm{AcAc}$ $(1.0: 0.5: 1.0)$. In addition, MEU was copolymerized with ethylene oxide (EO), propylene oxide
(PO), and $n$-hexene oxide (HO) to polymers with high MEU content and high molecular weight.

Polymerization of methyl $\omega$-epoxyalkanoates was investigated with a number of initiator systems (eq 3 ), of which the $\mathrm{AlEt}_{3}-\mathrm{H}_{2} \mathrm{O}-\mathrm{AcAc}$ prepared by addition of AcAc, $\mathrm{AlEt}_{3}$, and water in diethyl eter gave the only highly efficient initiator.

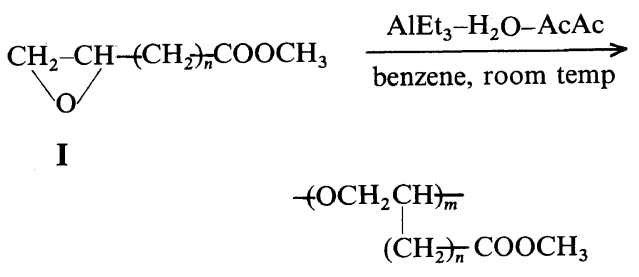

II

$$
n=1,2,5,8
$$

As compared to the homopolymerization of cyclic ethers with comparable side-chain length of an aliphatic side chain (e.g., $\mathrm{PO}$ or $\mathrm{HO}$ ), the methyl $\omega$-epoxyalkanoates polymerized much slower as judged by the slow but steady increase of the viscosity of the reaction mixture. Consequently, longer reaction times ( $2-3$ weeks) were necessary to obtain polymers of high molecular weight. We did find that under the same conditions and with the same type of solvent, monomer concentration and initiating mixture, high-molecular-weight polymers of EO and PO could be obtained in 1 to 3 days. The 
copolymerization of methyl $\omega$-epoxyalkanoates with $\mathrm{PO}$ or $\mathrm{HO}$ was observed qualitatively to have rates of polymerization intermediate between the two extremes.

It is interesting to compare the relative comonomer composition of the PO-MEU (78:22) copolymer with that of the PO-EG $(96: 4)$ copolymer which we recently described. ${ }^{9}$ The increased reactivity of the MEU $(n=8)$ is in all likelihood due to the role of the spacer group in separating the ester functionality and its electron withdrawing character from the epoxy group. We therefore believe the slower rate of homopolymerization of methyl $\omega$ epoxyalkanoates and their reactivity in copolymerization is a combination of electronic and steric effects with the electronic effect dominating in the case where $n=0$ to $n=2$, while steric hindrance is the controlling factor for the polymerization of $\omega$ epoxyalkanoates with longer alkyl chains as spacer groups. This is further demonstrated by comparing the compositions of the PO-MEU copolymer (which was analyzed as $78: 22$ ) with the initial monomer feed mixture of PO-MEU $(70: 30)$ which indicates a similar overall reactivity of the two comonomers in spite of the substantial difference in the substituent structures.

The exact structure of the active initiator system produced by properly reacting an aluminumalkylwater mixture and a chelating agent AcAc is not known. Our systems were prepared by mixing $\mathrm{AlR}_{3}-\mathrm{H}_{2} \mathrm{O}-\mathrm{AcAc}$ in the ratio of $1.0: 0.5: 1.0$. If the ratio is changed, even slightly, the initiating system is less active. It is critical that the components which gave the final initiator were added in the proper sequence, otherwise an initiator solution was produced that was inactive for the polymerization of methyl $\omega$-epoxyalkanoates. Thus, AcAc was prereacted with $\mathrm{AlEt}_{3}$ in diethyl ether followed by addition of the desired quantity of $\mathrm{H}_{2} \mathrm{O}$. This sequence produced a highly active homogeneous initiator solution that maintained its activity for several weeks. In contrast, pre-reaction of $\mathrm{AlEt}_{3}$ with $\mathrm{H}_{2} \mathrm{O}$, preceding the addition of AcAc, resulted in the formation of a heterogeneous mixture that exhibited no activity in homopolymerization of MEU or ECH.

The polymerization of MEU with modified aluminumalkyl initiator was carried out in benzene solution at room temperature and gave a polymer in about $50 \%$ yield; additional experiments gave the polymer in even higher yields. Carbon and hydrogen analysis of the polymer was in excellent agreement with the calculated values; the ash content was less than $0.05 \%$ indicating complete

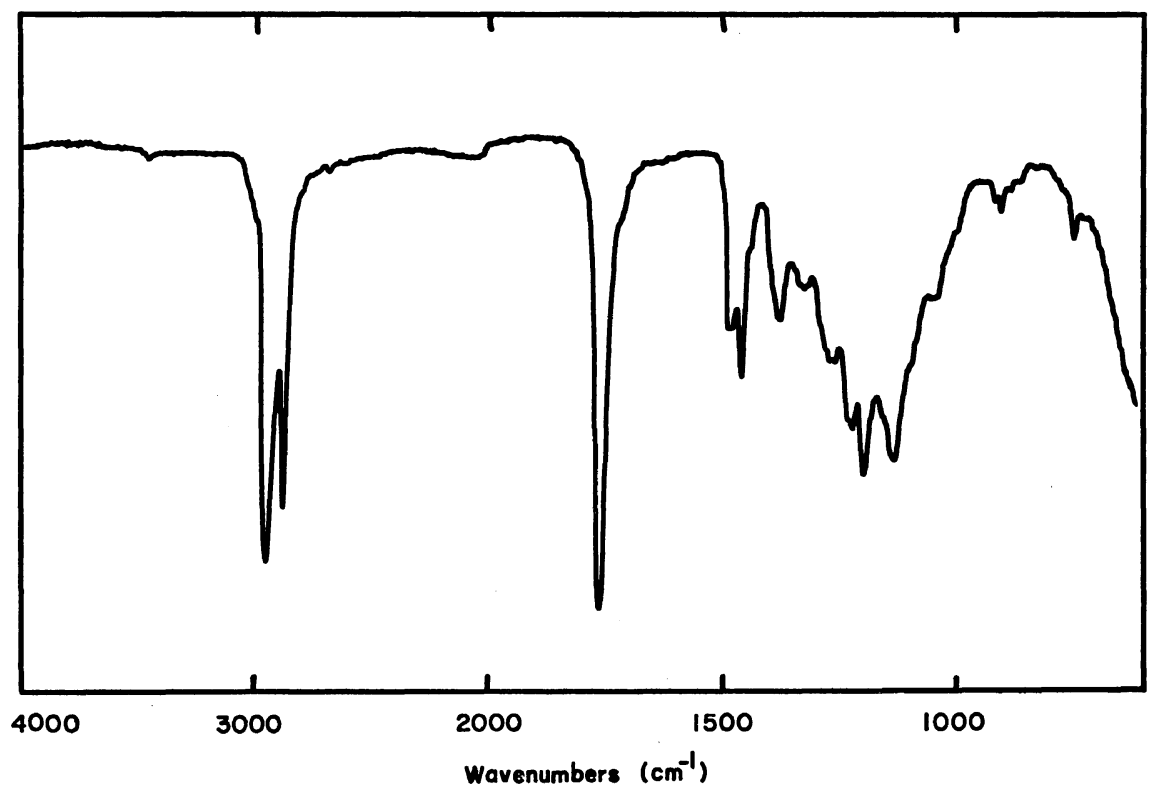

Figure 1. IR spectrum of poly(methyl 10,11-epoxyundecanoate). 


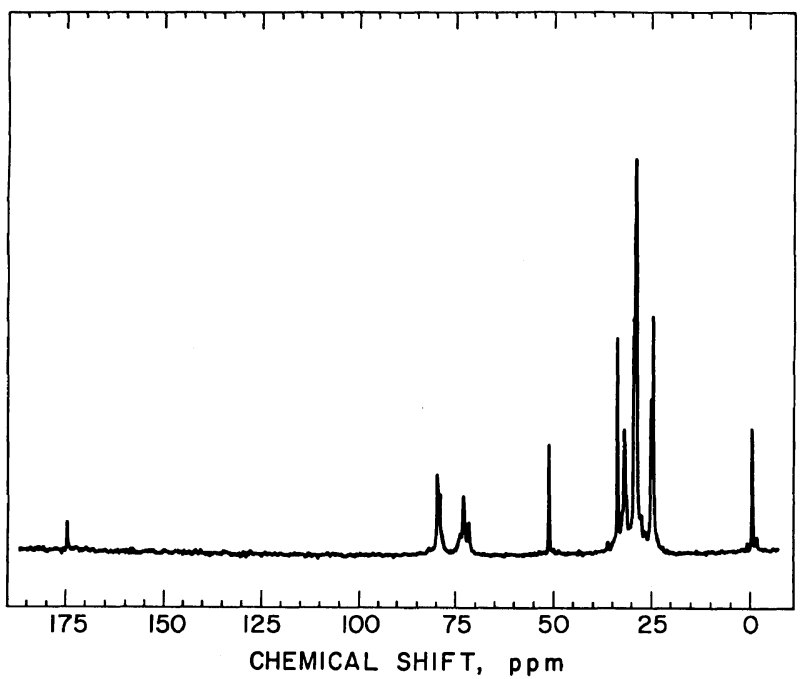

Figure 2. ${ }^{13} \mathrm{C}$ NMR spectrum of poly(methyl 10,11-epoxyundecanoate).

removal of initiator residues; inherent viscosity of the polymer was determined to be $1.8 \mathrm{dl} \mathrm{g}^{-1}$ (in chloroform). The infrared spectrum $(\mathrm{C}=\mathrm{O}$ stretch) of the polymer showed the ester group at $1735 \mathrm{~cm}^{-1}$ and other bands characteristic of a polymer of this structure (Figure 1). The ${ }^{13} \mathrm{C}$ NMR spectrum also showed chemical shifts characteristic for a polymer with the structure of a substituted polyether (Figure 2). Details and exact numerical values of the ${ }^{13} \mathrm{C}$ NMR chemical shift data of homopolymers of $\omega$ epoxyalkanoates and copolymers with $\mathrm{PO}$ and $\mathrm{HO}$ are tabulated in Table III.

The homopolymer of MEU was also analyzed by GPC in THF solution at room temperature and an $M_{w}$ of 578000 with an $M_{n}$ of 248000 was found $\left(M_{w} / M_{n}=2.3\right)$. Analysis of the thermal behavior of this polymer by DSC showed the polymer to have a $T_{\mathrm{g}}$ of $-32^{\circ} \mathrm{C}$. An additional endothermic transition after some annealing and rescanning was found around $90^{\circ} \mathrm{C}$, which may indicate some crystallization of the side group.

Homopolymerizations of $\omega$-epoxyalkanoates have also been achieved with MEO $(n=5)$ and MEP $(n=2)$. The ${ }^{13} \mathrm{C}$ NMR chemical shift data of the homopolymer of MEO is described in Table III. For comparison, the data for the polymers of $\mathrm{PO}$ and $\mathrm{HO}$ are also tabulated. The ${ }^{13} \mathrm{C}$ chemical shift values of individual carbon atoms are indicated as A, B, C for poly(PO) and poly(HO) and as 1, 2, 3, 4, etc., for the $\omega$-epoxyalkanoate polymers. The numbering of the individual carbon atoms was adopted for homopolymers of methyl $\omega$-epoxyalkanoates and their copolymers with substituted (but not functionally substitued) epoxides.

With our initiator system and in benzene solution, we were also able to prepare copolymers of $\omega$ epoxyalkanoates where $n=1,2,5,8$ with $\mathrm{PO}$ and HO (eq 4).

$$
\begin{aligned}
& \underbrace{\mathrm{CH}_{2}-\mathrm{CH}-\mathrm{R}}_{\mathrm{O}}+\underbrace{\mathrm{CH}_{2}-\mathrm{CH}-\left(\mathrm{CH}_{2}\right)_{n}-\mathrm{COOCH}_{3} \longrightarrow}_{\mathrm{O}}
\end{aligned}
$$

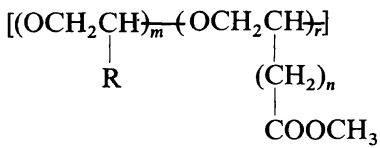

The ${ }^{13} \mathrm{C}$ NMR chemical shift data of the copolymers of epoxides and $\omega$-epoxyalkanoates are shown in Table III. The chemical shifts of the oxyethylidene backbone carbon atoms are located between 73 and $80 \mathrm{ppm}$, that of the methyl carbon atoms between 14 and $18 \mathrm{ppm}$ and that of the methylene carbon atoms between 25 and $32 \mathrm{ppm}$. The ${ }^{13} \mathrm{C}$ chemical shift value of the carbon atom of the ester function is at $51 \mathrm{ppm}$ and that of the carbonyl carbon atom at 173 ppm.

Very recently we have also demonstrated that our initiator system is very effective for the homopolymerization of EO and the copolymerization of EO 
Table III. ${ }^{13} \mathrm{C}$ NMR chemical shift data of substituted poly(ethylene oxides) ${ }^{\mathrm{a}}$ (Polymers of epoxides and $\omega$-epoxyalkanoates)

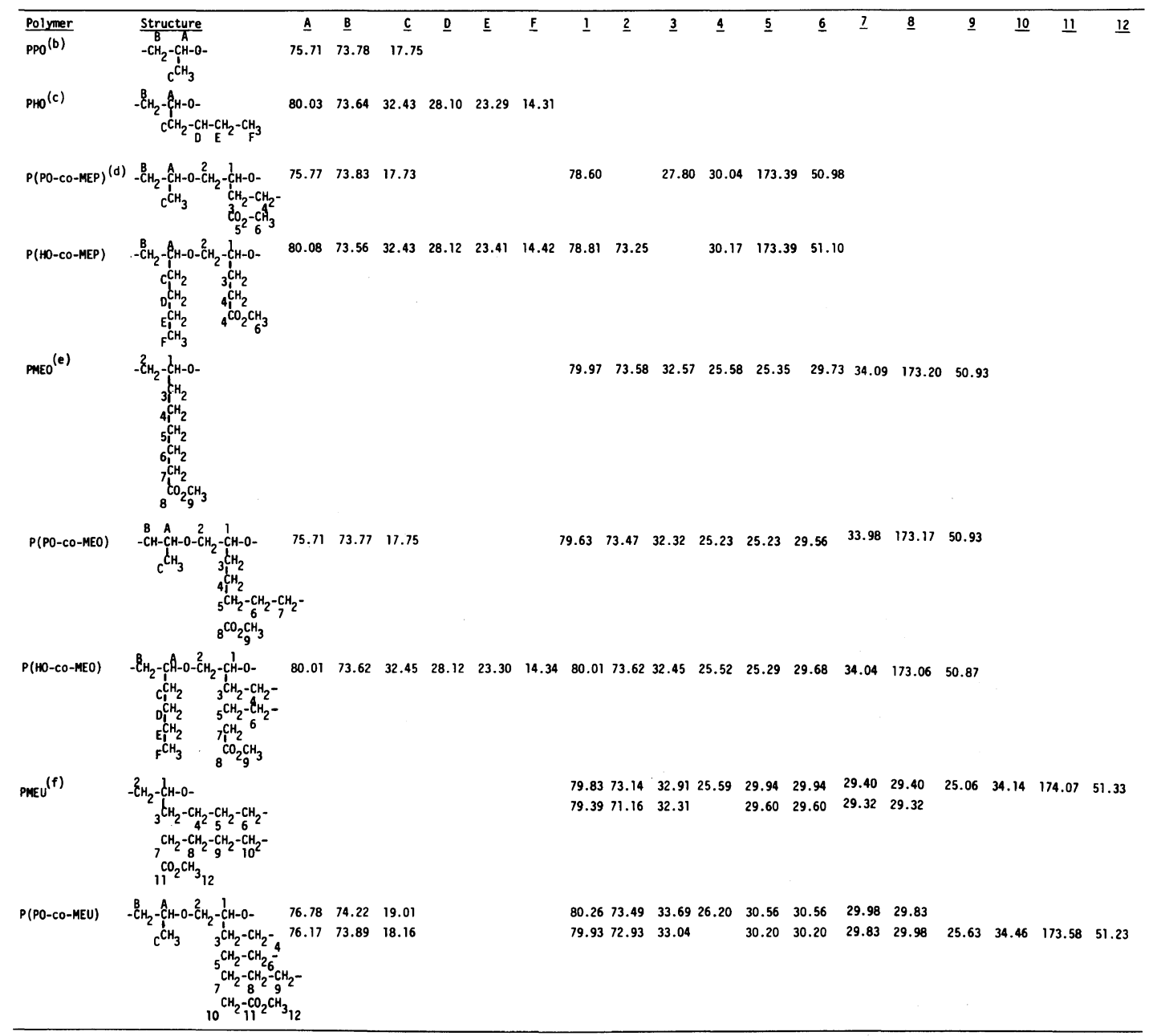

${ }^{a}$ ppm downfeld from TMS in benzene. ${ }^{b}$ PPO, poly(propylene oxide). ${ }^{c}$ PHO, poly(1,2-epoxyhexane). ${ }^{d}$ MEP, methyl 4,5-epoxypentanoate. ${ }^{\mathrm{e}} \mathrm{MEO}$, methyl 7,8-epoxyoctanoate. ${ }^{\mathrm{f}} \mathrm{MEU}$, methyl 10,11-epoxyundecanoate.

with MEU (Figure 3 for the infrared spectrum and Figure 4 for the ${ }^{13} \mathrm{C}$ NMR spectrum). Analysis of the infrared spectrum indicated that the copolymer of EO and MEU has about $15 \mathrm{~mol} \%$ of MEU incorporated in the copolymer which was obtained from a feed ratio of $70: 30(\mathrm{~mol} \%)$ EO-MEU.

All the ${ }^{13} \mathrm{C}$ NMR spectra of the polymers described in this work are consistent with the chemical structures of the polymers. Based on the ${ }^{13} \mathrm{C}$ NMR chemical shift data of these polymers, it seems likely that both head-to-head and head-to-tail linkages are present in the polyether backbone. We have not attempted to determine either the relative amounts of these two linkages in the homopolymers or copolymers or the comonomer distribution of the copolymers. The previously reported detailed ${ }^{13} \mathrm{C}$ NMR analysis of PPO has already described the irregular nature of the polyether backbone. ${ }^{18}$ In our copolymers we not only have problems of head-tohead versus head-to-tail arrangements, but also comonomer distribution and stereochemistry. 


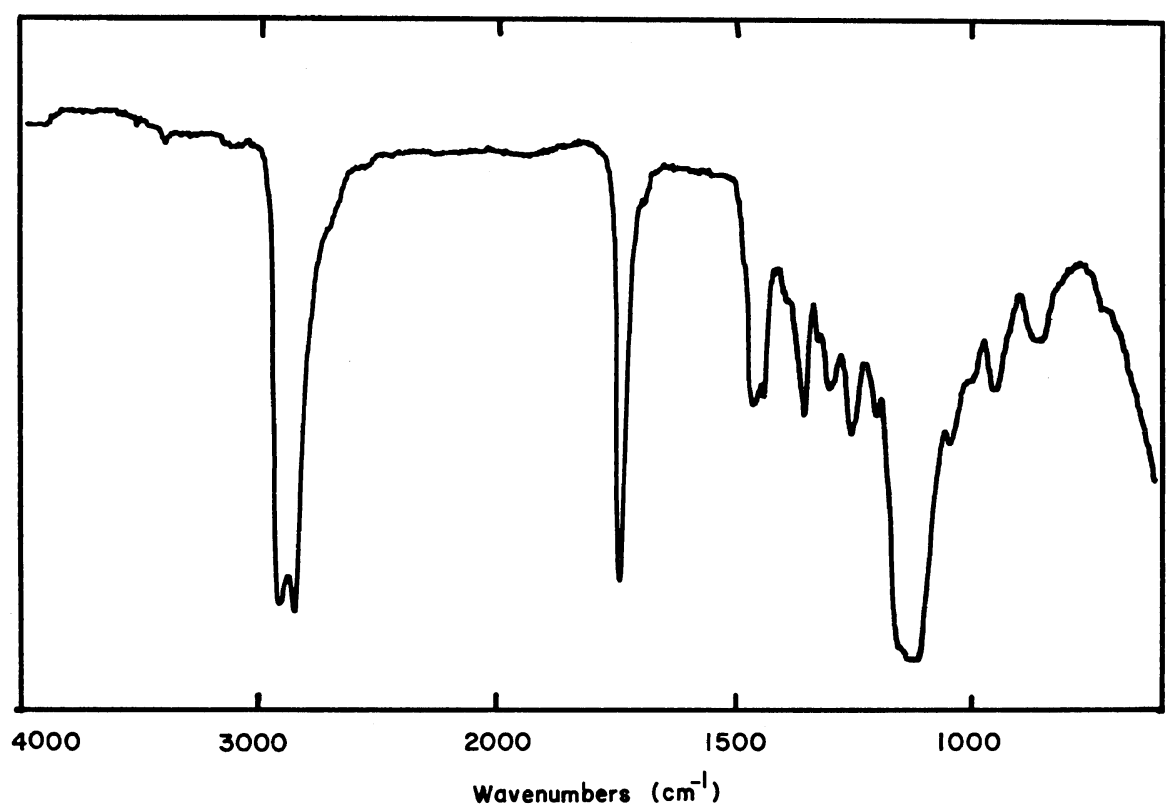

Figure 3. IR spectrum of copolymer of ethylene oxide and methyl 10,11-epoxyundecanoate.

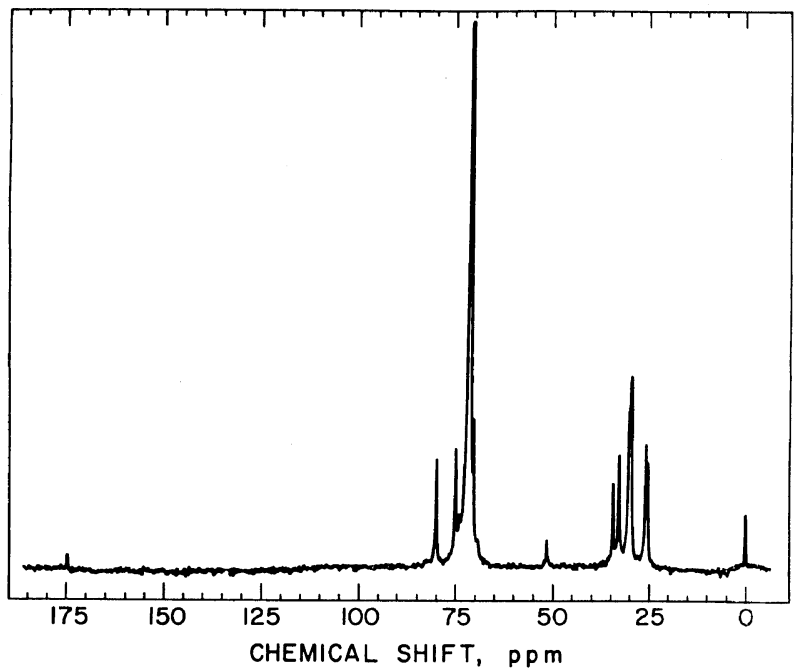

Figure 4. ${ }^{13} \mathrm{C}$ NMR spectrum of copolymer of ethylene oxide and methyl 10,11-epoxyundecanoate.

\section{Attempted Polymerization of Methyl $\omega$-Epoxy- alkanoates with Cationic Initiators}

We have attempted a number of ring-opening polymerizations of methyl $\omega$-epoxyalkanoates with typical cationic initiators such as $\mathrm{SbCl}_{5}, \mathrm{BF}_{3}$ etherate, and $\mathrm{CF}_{3} \mathrm{SO}_{3} \mathrm{H}$; no high polymers were formed in any of these monomer-initiator mixtures (Table IV). It is, however, quite possible that oligomers, particularly cyclic dimers and/or higher cyclic oligomers were formed as no monomer was detected at the end of the reactions. 
Table IV. Polymerization ${ }^{\mathrm{a}}$ of methyl $\omega$-epoxyalkanoates with cationic initiators ${ }^{\mathrm{b}}$

\begin{tabular}{cl}
\hline Monomer & $\begin{array}{c}\text { Initiator } \\
(\% \text { of monomer feed })\end{array}$ \\
\hline $\mathrm{MEB}^{\mathrm{c}}$ & $\mathrm{BF}_{3} \cdot \mathrm{O}\left(\mathrm{C}_{2} \mathrm{H}_{5}\right)_{2}(2 \%)$ \\
$\prime \prime$ & $\mathrm{CF}_{3} \mathrm{SO}_{3} \mathrm{H}(2 \%)$ \\
$\prime \prime$ & $\mathrm{SbCl}_{5}(2 \%)$ \\
$\mathrm{MEP}^{\mathrm{d}}$ & $\mathrm{BF}_{3} \cdot \mathrm{O}\left(\mathrm{C}_{2} \mathrm{H}_{5}\right)_{2}(2 \%)$ \\
$\prime \prime$ & $\mathrm{CF}_{3} \mathrm{SO}_{3} \mathrm{H}(2 \%)$ \\
$\prime \prime$ & $\mathrm{SbCl}_{5}(2 \%)$ \\
$\mathrm{MEO}^{\mathrm{e}}$ & $\mathrm{BF}_{3} \cdot \mathrm{O}_{2}\left(\mathrm{C}_{2} \mathrm{H}_{5}\right)_{2}(2 \%)$ \\
$\prime \prime$ & $\mathrm{CF}_{3} \mathrm{SO}_{3} \mathrm{H}(2 \%)$ \\
\hline$"$ & $\mathrm{SbCl}_{5}(2 \%)$ \\
$\mathrm{MEU}^{\mathrm{f}, \mathrm{g}}$ & $\mathrm{BF}_{3} \cdot \mathrm{O}_{2}\left(\mathrm{C}_{2} \mathrm{H}_{5}\right)_{2}(2 \%)$ \\
$\prime \prime$ & $\mathrm{CF}_{3} \mathrm{SO}_{3} \mathrm{H}(2 \%)$ \\
\hline & $\mathrm{SbCl}_{5}(2 \%)$ \\
\hline
\end{tabular}

a No polymer obtained.

b Polymerization temperature, $25^{\circ} \mathrm{C}$; polymerization time, 30 days; concentration, $25-40$ percent; solvent, nitrobenzene.

c MEB, methyl 3,4-epoxybutanoate.

d MEP, methyl 4,5-epoxypentanoate.

e MEO, methyl 7,8-epoxyoctanoate.

f MEU, methyl 10,11-epoxyundecanoate.

g Solvent for MEU polymerization, dichloromethane.

\section{REFERENCES}

1. J. Furukawa and T. Saegusa, "Polymerization of Aldehydes and Oxides," Wiley (Interscience), New
York, N.Y., 1963.

2. K. C. Frisch and S. L. Reegan, "Ring-Opening Polymerization," Marcel Dekker, New York, N.Y., 1969.

3. K. V. Martin and O. Vogl, U.S. Patent 3284411 (1966).

4. L. DeMejo, W. J. MacKnight, and O. Vogl, Polymer, 19, 959 (1978).

5. L. DeMejo, W. J. MacKnight, and O. Vogl, Polym. $J ., 11,15$ (1979).

6. H. Sumitomo and K. Kobayashi, J. Polym. Sci., A-1, 4, 907 (1966).

7. T. Saegusa, T. Kobayashi, S. Kobayashi, S. LundCouchman, and O. Vogl, Polym. J., 11, 463 (1979).

8. D. Tirrell, O. Vogl, T. Kobayashi, S. Kobayashi, and T. Saegusa, Polym. Prepr., Am. Chem. Soc., Div. Polym. Chem., 20, 794 (1979).

9. D. Tirrrell, O. Vogl, T. Kobayashi, S. Kobayashi, and T. Saegusa, Macromolecules, in press.

10. S. Matsumoto, K. Komatsu and K. Igarashi, "RingOpening Polymerization," T. Saegusa and E. Gothals, Ed., Am. Chem. Soc. Symp. Ser., 59, 303 (1977).

11. B. N. Hendy, S. Afr. Patent 6701 454; Chem. Abstr., 70, 78547y (1969).

12. E. J. Vandenberg, U.S. Patent 3135705 (1964).

13. E. J. Vandenberg, U.S. Patent 3106549 (1963).

14. P. Dreyfuss and J. P. Kennedy, Anal. Chem., 47, 771 (1975).

15. N. N. Schwartz and J. H. Blumberg, J. Org. Chem., 29, 1976 (1964).

16. W. D. Emmons and A. S. Pagano, J. Am. Chem. Soc., 77, 89 (1955).

17. H. Y. Aboul-Enein, Synth. Commun., 4, 255 (1974).

18. J. Schaefer, Macromolecules, 2, 533 (1969). 